\title{
Radiation Induced Crystallinity Changes in Linear Polyethylenes: Long Term Aging Effects
}

\author{
S. K. Bhateja, ${ }^{\dagger}$ E. H. Andrews, ${ }^{*}$ and S. M. Yarbrough ${ }^{* *}$ \\ Corporate Research Technology Development Laboratory, \\ 219-1-01, 3M/3M Center, Saint Paul, MN 55144, USA \\ * Materials Department, Queen Mary College, Mile End Road, \\ London E1 4NS, England \\ **208-1-01, CRPTL, 3M/3M Center, Saint Paul, \\ $M N 55144, U S A$
}

(Received January 30, 1989)

\begin{abstract}
It has been shown previously that linear polyethylenes undergo an increase in crystallinity and peak melting temperature after irradiation, the magnitude of the effects being dependent upon the dose and the molecular weight of the polymer. The effects were also found to change with time after irradiation (aging) up to 31 months. These changes have now been followed up to aging times of 112 months. The heats of fusion (thus the crystallinities) continue to increase over this extended time-span, but the peak melting temperatures rise to a maximum immediately after irradiation and then fall progressively with the passage of time. The results are attributed to tie molecule scission with the consequent relaxation of local stresses, followed by the slow growth of new crystal lamellae.

KEY WORDS Radiation / Electron Beam Radiation / Aging, Heat of Fusion / Differential Scanning Calorimeter / Crystallinity Changes / Linear Polyethylenes / Ultra-high Molecular Weight Polyethylene /
\end{abstract}

Although the irradiation of polyethylene and other polymers has been a subject of study over many years, it is only recently that the effects discussed in this paper have been documented. An increase in crystallinity after irradiation was first reported by Gee and Melin $^{1}$ who found a continuous increase in density with radiation dose up to $75 \mathrm{Mrad}$ of gamma irradiation in polyethylene. In polypropylene, however, density decreased at first (up to $25 \mathrm{Mrad}$ ) before rising again. Other investigators $^{2-11}$ found a similar density increase in their studies of ultra-high molecular weight polyethylene (UHMWPE) used for medical prostheses. More recently, Gal et al. ${ }^{12}$ have demonstrated an increase in crystallinity with irradiation in linear low-density polyethylene (LLDPE), though not in branched LDPE. The increase was slightly enhanced when antioxidants were incorporated in the material. Aslanian et al., ${ }^{13}$ however, found an increase in crystallinity with gamma irradiation even in branched LDPE.

It should be emphasized that many studies have found only a decrease in crystallinity, in many different polymers follwing irradiation, and a number of such references are cited in the reviews by Dole ${ }^{14}$ and Mikherjee et al. ${ }^{15}$

Bhateja, Andrews and Young ${ }^{5}$ demonstrated that the enhancement of crystallinity was found in both UHMWPE and normal high density polyethylene (HDPE) and that it

+ The work was first initiated by S.K.B. in Central Research, The Dow Chemical Company, Midland, Michigan, USA. The kind permission by Dow to continue the study is gratefully appreciated. 
was accompanied by a rise in the peak melting temperature of the polymers as measured by differential scanning calorimetry (DSC). It was proposed that irradiation severed tie molecules traversing the amorphous regions, allowing the existing crystalline lamellae to increase in perfection (though not in thckness) and new lamellae to grow.

In a subsequent paper, Bhateja $^{6}$ remeasured the heats of fusion and melting endotherms of the same irradiated materials and found that the heats of fusion continued to rise with time at ambient temperature, but that in contrast the peak melting temperatures $\left(T_{\mathrm{m}}\right)$ had decreased relative to their initial postirradiation values. The period covered by this work was 31 months. While the continued rise in heat of fusion was not totally surprising, the behavior of $T_{\mathrm{m}}$ was most puzzling.

It has now been possible to follow the changes in heat of fusion and peak melting temperature of the meterials first discussed in ref 5 over an extended time period up to 112 months, and results are reported in this paper. We have also reviewed the explanations advanced previously to account for these changes and put forward a somewhat modified scenario of the mechanisms involved.

\section{MATERIALS AND IRRADIATION}

The materials examined in the present paper were the same as those used in ref 5 and 6 , and were designated $\mathrm{A}, \mathrm{B}$, and $\mathrm{C}$. All materials were supplied by the Dow Chemical Company. Materials A and B were experimental UHMWPE resins and material $C$ was normal molecular weight linear polyethylene. Some of the characteristics of these resins are given in Table I.

The resins were compression molded at ca. $200 \mathrm{deg} \mathrm{C}$ (see ref 5 for details) and exposed to high energy electron radiation in a Van de Graaff accelerator with $2 \mathrm{MeV}$ electrons at a beam current of $250 \mu \mathrm{A}$, delivering $0.5 \mathrm{Mrad} / \mathrm{pass}$ through the beam. Core temperatures in the sheets during irradiation rose to $50 \mathrm{degC}$ after $12 \mathrm{Mrad}$ and to an equilibrium value of $73 \mathrm{degC}$ after $85 \mathrm{Mrad}$.

\section{AGING AND EVALUATION}

Materials were "aged" under somewhat fluctuating ambient conditions since orginally, being unaware of the existence of aging effects, we had no intention of studying the effects of aging time or aging conditions such as humidity, exposure to light, etc. Materilas were stored in a normal laboratory atmosphere (temperature $\sim 23 \pm 2{ }^{\circ} \mathrm{C}$ ).

Specimens were evaluated in a Perkin-Elmer DSC2 calorimeter at $10 \mathrm{degC} \mathrm{min}^{-1}$ using a specimen size of $3 \mathrm{mg}$. All data were collected on the first scan since the effects under study are destroyed by melting and recrystallization. From the DSC thermograms, the peak melting

Table I. Materials examined together with some of their physical, thermal, and mechanical characteristics

\begin{tabular}{|c|c|c|c|c|c|c|}
\hline \multirow[t]{2}{*}{ Material } & \multirow[t]{2}{*}{ Designation } & $\begin{array}{l}\text { Reported } \\
\text { intrinsic } \\
\text { viscosity }\end{array}$ & \multirow[t]{2}{*}{$\bar{M}_{w}$} & \multirow{2}{*}{$\frac{\text { Density }^{\mathrm{a}}}{\mathrm{g} \mathrm{cm}^{-3}}$} & \multirow{2}{*}{$\frac{\begin{array}{c}\text { Peak } \\
\text { melting } \\
\text { temperature }\end{array}}{{ }^{\circ} \mathrm{C}}$} & \multirow{2}{*}{$\begin{array}{r}\text { Young's } \\
\text { modulus }\end{array}$} \\
\hline & & $\mathrm{dlg}^{-1}$ & & & & \\
\hline UHMW PE1 & A & 19.8 & $>3 \times 10^{6}$ & 0.927 & 134 & 1.0 \\
\hline UHMW PE2 & B & 14.8 & $>2 \times 10^{6}$ & 0.932 & 135.5 & 1.2 \\
\hline HDPE & $\mathrm{C}$ & ca. 2.7 & $2 \times 10^{5}$ & 0.956 & 136.5 & 1.7 \\
\hline
\end{tabular}

a Densities are those of compression molded sheets.

b Peak melting temperatures are from DSC scans at $20^{\circ} \mathrm{C} \mathrm{min}^{-1}$. 
temperature $T_{\mathrm{m}}$ and the heat of fusion $h_{\mathrm{f}}$ were calculated in the usual manner. The data presented are averages from 3 or 4 specimens at each condition and the reproductibility was within $\pm 1^{\circ} \mathrm{C}$ for $T_{\mathrm{m}}$ and $\pm 4 \mathrm{Jg}^{-1}$ for $h_{\mathrm{f}}$. The crystallinity can be defined as ${ }^{8,9}$

$$
C=h_{\mathrm{f}} / h_{\mathrm{f}}^{\prime}
$$

where $h^{\prime}{ }_{\mathrm{f}}$ is the heat of fusion of $100 \%$ crystalline material. The latter figure was taken as 291 $\mathrm{J} / \mathrm{g}\left(69 \mathrm{cal} \mathrm{g}^{-1}\right)$.

\section{RESULTS}

\section{Heats of Fusion}

Figures $1-3$ show the heats of fusion of the specimens of all three materials as a function of radiation dose at various times after irradiation as indicated on the graphs. Figure 1 refers to material $\mathrm{A}$, the highest molecular weight material which has the lowest initial heat of fusion. For $16 \mathrm{Mrad}$ speciments $h_{\mathrm{f}}$ had increased by some $10 \%$ one day after irradiation, and a similar increase had occurred at higher doses. Nine months later the increase was around $20 \%$ for the $16 \mathrm{Mrad}$ and $64 \mathrm{Mrad}$ samples but smaller at higher doses.

With the passage of time this trend is maintained and at 112 months the 16 Mrad sam- ples have increased their heat of fusion by a staggering $60 \%$, with systematically smaller rises for higher doses (e.g., 30\% at $128 \mathrm{Mrad}$ ). It is clear that there is a very long term growth in either the perfection or the amount of the crystalline phase (or of both), a process which is optimized at the intermediate irradiation dose of 16 Mrad.

Material B (Figure 2) behaves in an essentially similar manner. After one day, regardless of dose, $h_{\mathrm{f}}$ had increased by about $15 \%$, but after 112 months a $50 \%$ rise was recorded for the $16 \mathrm{Mrad}$ samples, with progressively smaller rises for the higher dose samples. For both UHMWPE materials the maximum crystallinity developed after 112 months was around $72 \%$ compared with an initial value for the unirradiated HDPE of $65 \%$.

Results for the HDPE (material C) are shown in Figure 3 and are consistent with those for UHMWPE, though less spectacular. One day after irradiation the observed increase in $h_{\mathrm{f}}$ is very small at all doses, but after 9 months the $16 \mathrm{Mrad}$ samples have increased their $h_{\mathrm{f}}$ by $6 \%$ to $8 \%$ and after 79 months by $16 \%$. A maximum crystallinity of $78 \%$ is thereby achieved. There is a slight suggestion that the $h_{\mathrm{f}}$ declines again after 79 months, but this may be due to sample to sample varia-

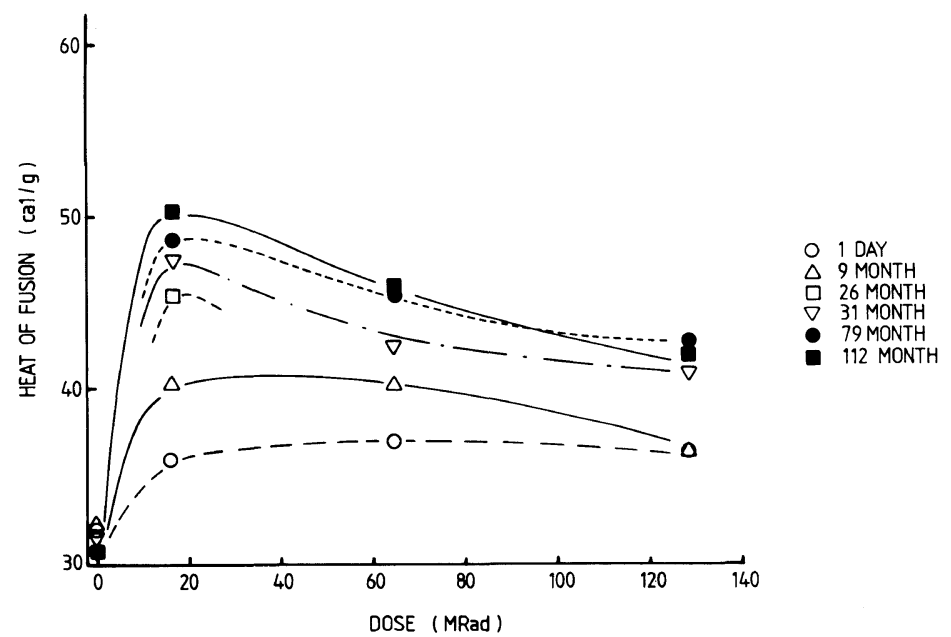

Figure 1. Material A: Effect of radiation dose on the heat of fusion at various aging times. 


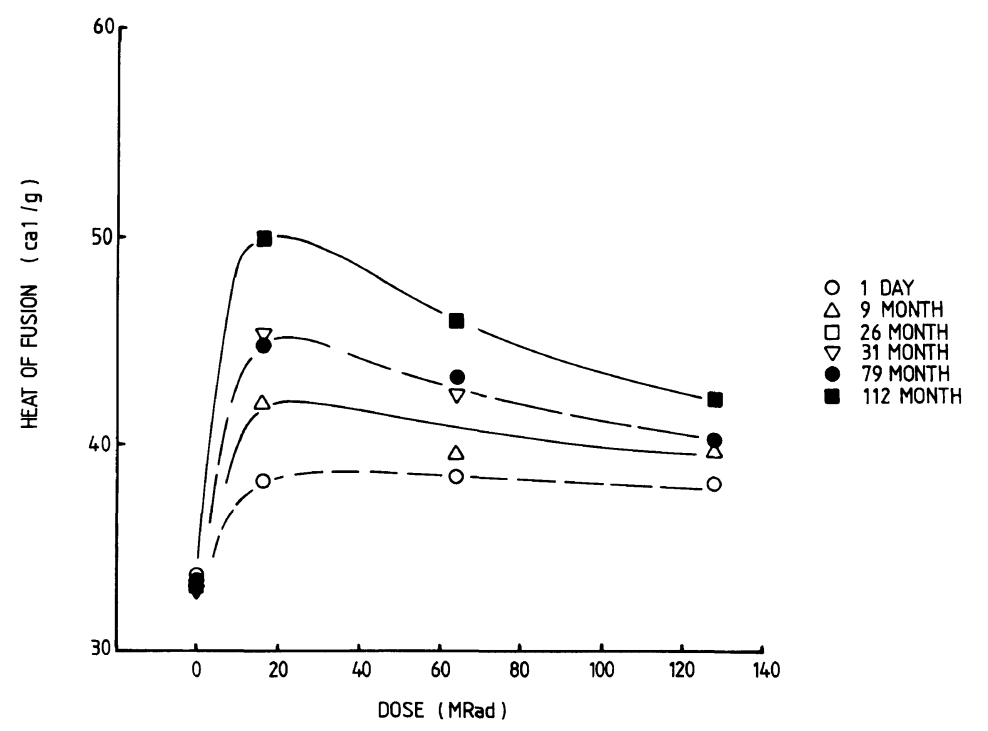

Figure 2. Material B: Effect of radiation dose on the heat of fusion at various aging times.

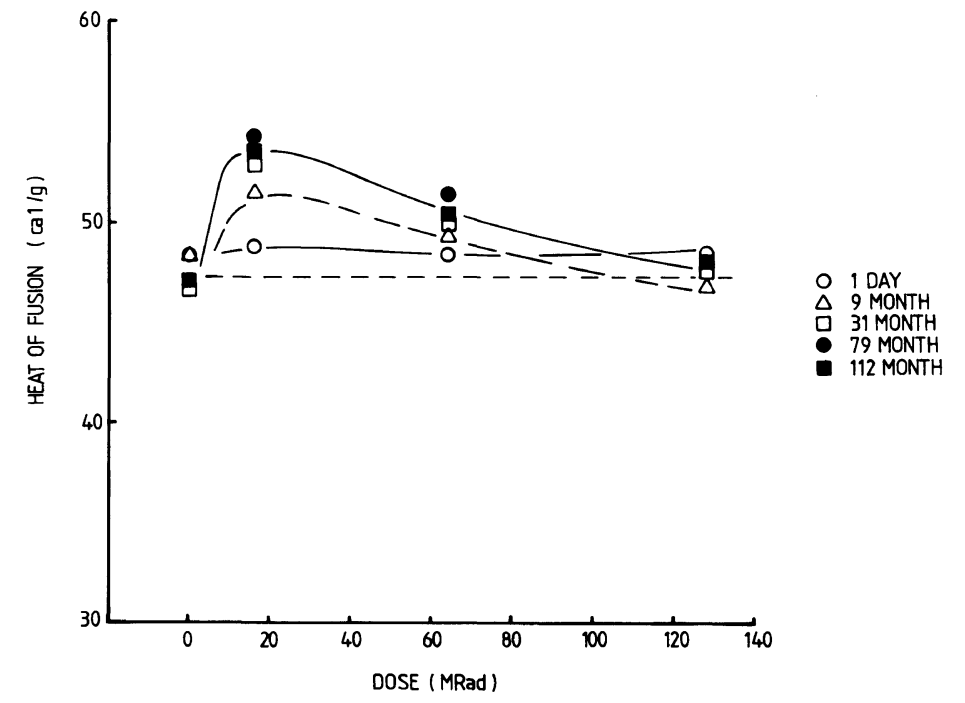

Figure 3. Material C: Effect of radiation dose on the heat of fusion at various aging times.

tion. Certainly there is no further increase in $h_{\mathrm{f}}$ between 79 and 112 months aging. As in the case of UHMWPE materials, radiation doses in excess of $16 \mathrm{Mrad}$ produce smaller rises in $h_{\mathrm{f}}$ at all aging times and no increase at all is observed for 128 Mrad samples regardless of age. Nevertheless, the effects in HDPE are in all respects similar, qualitatively, to those in UHMWPE.

The data for 16 Mrad specimens are replotted in Figure 4 as heat of fusion versus aging time for all three materials. Most of the increase in $h_{\mathrm{f}}$ occurs over the first 30 months, after which the materials stabilize. The final $h_{\mathrm{f}}$ values (and therefore crystallinities) for ultrahigh and normal molecular weight resins 


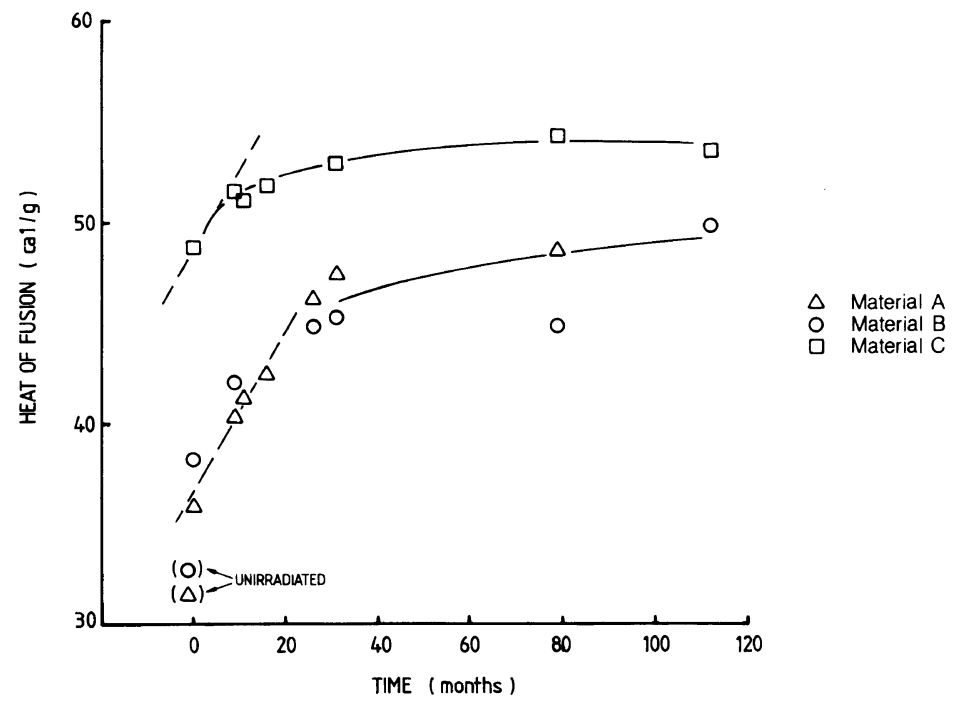

Figure 4. Effect of aging time on the heat of fusion of all three irradiated polyethylenes (exposed to a radiation dose of $16 \mathrm{Mrad}$ ).

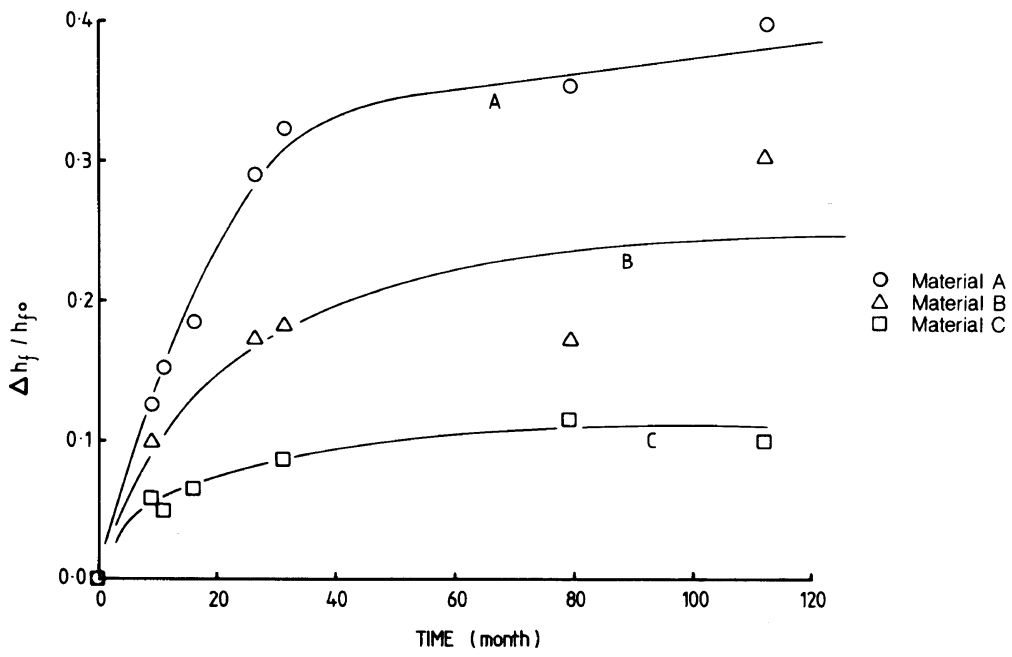

Figure 5. Data of Figure 4 replotted in terms of "normalized" heat of fusion showing the rise in heat of fusion due to aging alone for all three irradiated polyethylenes.

are much closer than their starting values, and it is not beyond possibility that the ultimate achievable crystallinities in UHMWPE would approach that of the HDPE, since $h_{\mathrm{f}}$ for the latter materials is still rising at 112 months. This ultimate value of nearly $80 \%$ may be the maximum achievable in polyethylene with normal lamellar thicknesses, due to the presence of fold surfaces.
Finally for the heat of fusion data, Figure 5 displays a normalized $h_{\mathrm{f}}$ increase defined as,

$$
\left(h_{\mathrm{f}}-h_{\mathrm{f} 0}\right) / h_{\mathrm{f} 0}
$$

where $h_{\mathrm{f} 0}$ refers to the unaged material, for the $16 \mathrm{Mrad}$ samples of all three resins. It is clear that the proportional increase in crystallinity is greatest in the material with the lowest initial crystallinity and least in that with the highest 
initial level. This underlines the basic implication of all these results, that the rise in $h_{\mathrm{f}}$, brought about by irradiation and subsequent aging, must involve crystallization of the previously amorphous phase and not solely an improvement in the perfection of the crystalline phase.

A further conclusion can be drawn from Figures 4 and 5 . After the intial rapid rise in $h_{\mathrm{f}}$ that occurs within the first day (we do not know exactly when), the post-irradiation crystallization occurs at a fairly constant rate for all materials (see broken line in Figure 4). The period over which this rate is maintained is, of course, smaller for HDPE (6 months, perhaps) than for UHMWPE (20 months), but it is clear that the process of crystal growth is the same in all materials, regardless of the initial degree of crystallinity. This is consistent with the idea that new lamellae are growing in the amorphous phase and does not accord with the alternative scenario of existing crystals increasing their perfection. (In the latter case we would expect $\mathrm{d} h_{\mathrm{f}} / \mathrm{d} t$ to be proportional to the existing degree of crystallinity and thus higher in HDPE than in UHMWPE and Figure 5 shows that this out of the question.)
What controls the rate of post-irradiation crystallization, whether temperature alone or on-going chain scission, will be discussed later. It is clear, however, that the rise in $h_{\mathrm{f}}$ during the first day is so rapid that it is unlikely to be due to the crystal growth process posited for the period to 20 months. We thus seem forced to propose that there are two distinct mechanisms for post-irradiation crystallization, namely a very short term process occurring during the first day and a long term process involving the growth of new lamellae and proceeding at a constant rate (independent of the original degree of crystallinity) over many months until the available amorphous material is exhausted.

\section{Peak Melting Temperatures}

The peak melting temperatures $T_{\mathrm{m}}$ are shown in Figures $6-8$ as functions of radiation dose for the three materials after different times, from one day to 112 months.

One day after irradiation UHMWPE material A (Figure 6) exhibits a rise in $T_{\mathrm{m}}$ from the unirradiated value of about $134 \operatorname{degC}$ to 139 $\operatorname{degC}$ for 16 Mrad samples and to $141 \mathrm{degC}$ for $64 \mathrm{Mrad}$ and $128 \mathrm{Mrad}$ samples. With the

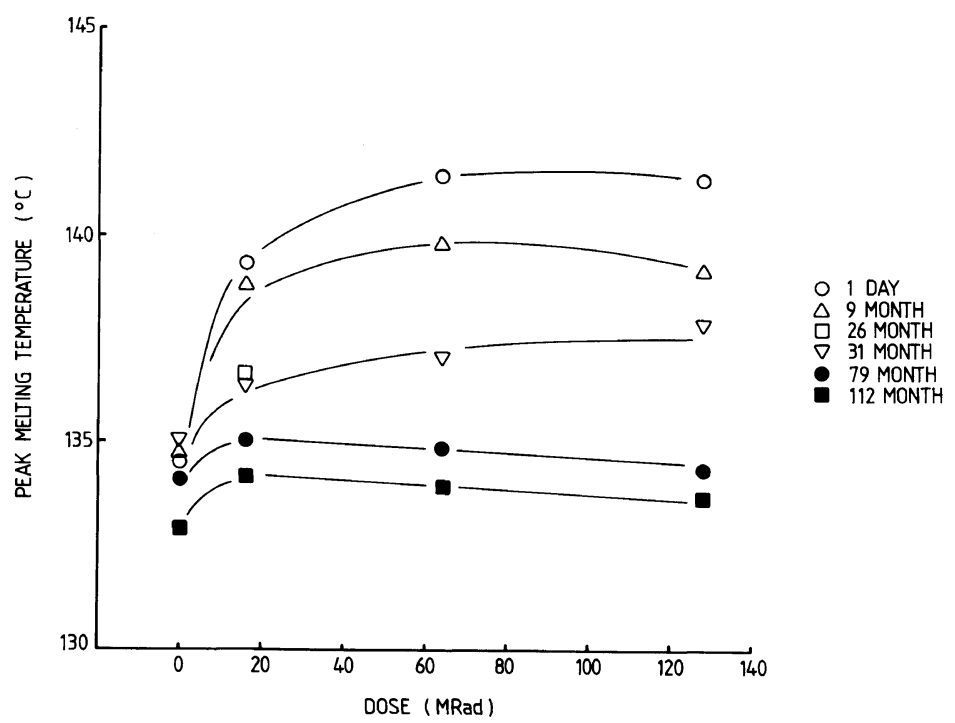

Figure 6. Material A: Effect of radiation dose on the peak melting temperature at various aging times. 


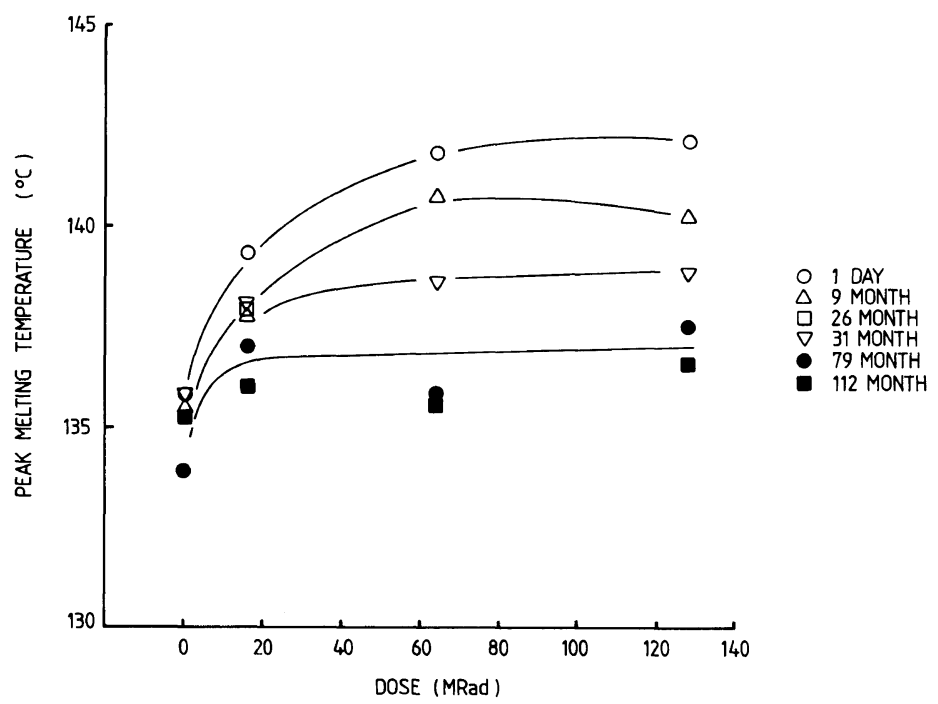

Figure 7. Material B: Effect of radiation dose on the peak melting temperature at various aging times.

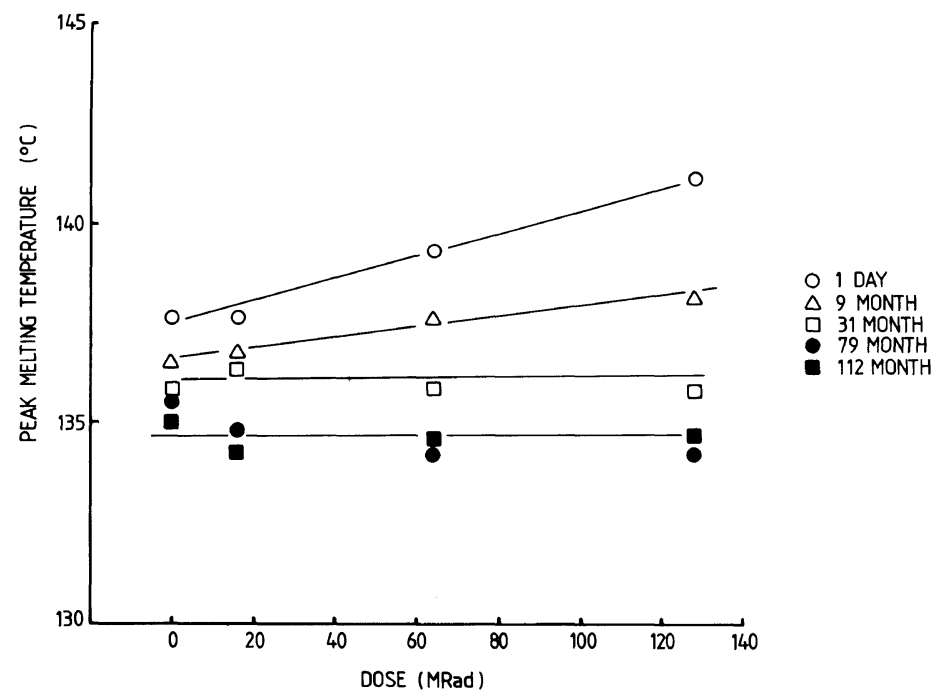

Figure 8. Material C: Effect of radiation dose on the peak melting temperature at various aging times.

passage of time, however, $T_{\mathrm{m}}$ begins to fall again until, after 112 months, the irradiationinduced $T_{\mathrm{m}}$ rise has been all but eliminated. (The unirradiated control shows a small drop in $T_{\mathrm{m}}$ after 112 months, but this may not be a genuine effect).

The same pattern of behvior is found for the higher levels of irradiation, though the initial rise in $T_{\mathrm{m}}$ is somewhat larger at $64 \mathrm{Mrad}$
( $T_{\mathrm{m}}=142 \mathrm{degC}$ after one day). At $128 \mathrm{Mrad}$, the effect is similar to that at $64 \mathrm{Mrad}$ but with a marginally lower $T_{\mathrm{m}}$. Figure 7 shows that the $T_{\mathrm{m}}$ behavior upon irradiation of (UHMWPE) polymer $B$ is virtually identical to that of polymer $\mathrm{A}$; the magnitude of the drop in $T_{\mathrm{m}}$ after 79 and 112 months, however, is smaller in polymer B than in polymer A.

HDPE (polymer C) also displays a 
radiation-induced increase in $T_{\mathrm{m}}$ which, for any given time after irradiation, is linear with dose (see Figure 8). Thus for this material the rise in $T_{\mathrm{m}}$ with dose is more gradual and higher doses do not reverse the effect. Also, after 31 months the decline in $T_{\mathrm{m}}$ with time is such that irradiated specimens no longer display a rise in $T_{\mathrm{m}}$ relative to the unirradiated material. (There is, in fact, a suggestion of a drop in $T_{\mathrm{m}}$ from the unirradiated value for 79 and 112 months, but this may be an artifact due to specimen-to-specimen variability). It is probably significant that the time scale for the disappearance of the $T_{\mathrm{m}}$ rise is similar to that required to attain a steady $h_{\mathrm{f}}$ value (i.e., some 30 months in HDPE and $>112$ months in UHMWPE). This suggests that the same mechanism is responsible for the time-dependent fall-off in $T_{\mathrm{m}}$ and for the time-dependent rise in $h_{\mathrm{f}}$.

Finally, Figure 9 shows how $T_{\mathrm{m}}$ decays with time for the $16 \mathrm{Mrad}$ samples of all three polymers Symbols in brackets also show the unirradiated values of $T_{\mathrm{m}}$ at zero time. The decay is almost linear and occurs at the same rate for all three polymers, that is, regardless of the initial values of $T_{\mathrm{m}}$ and crystallinity.

\section{DSC Thermograms}

The DSC thermograms for the polymers A, $\mathrm{B}$, and $\mathrm{C}$ up to 31 months post-irradiation have previously been published ${ }^{6}$ and consist in all cases of a single melting peak. We have now subjected the 79 and 112 month samples to thermal analysis and the results are reported here.

The HDPE continues to display a single smooth peak at 79 and 112 months postirradiation, but the UHMWPE polymers $A$ and $B$ reveal the emergence of a lowtemperature melting process with progressive aging. This is shown in Figure 10 for polymer $\mathrm{B}$ irradiated to $64 \mathrm{Mrad}$ and aged for 79 and 112 months, respectively. For the 112 month aged sample, the low-temperature shoulder or peak appears around $120 \mathrm{degC}$ for $16 \mathrm{Mrad}$ samples and appears to move downward slightly with increasing dose, to $117 \mathrm{degC}$ at $64 \mathrm{Mrad}$ and $115 \mathrm{degC}$ at $128 \mathrm{Mrad}$ (See Figure 11). The low-temperature peak develops with the passage of time but its position seems to depend only on dose, not on time. Very similar effects are observed in polymer A.

It is clear that part at least of the rise in $h_{\mathrm{f}}$ with post-irradation time is due to the

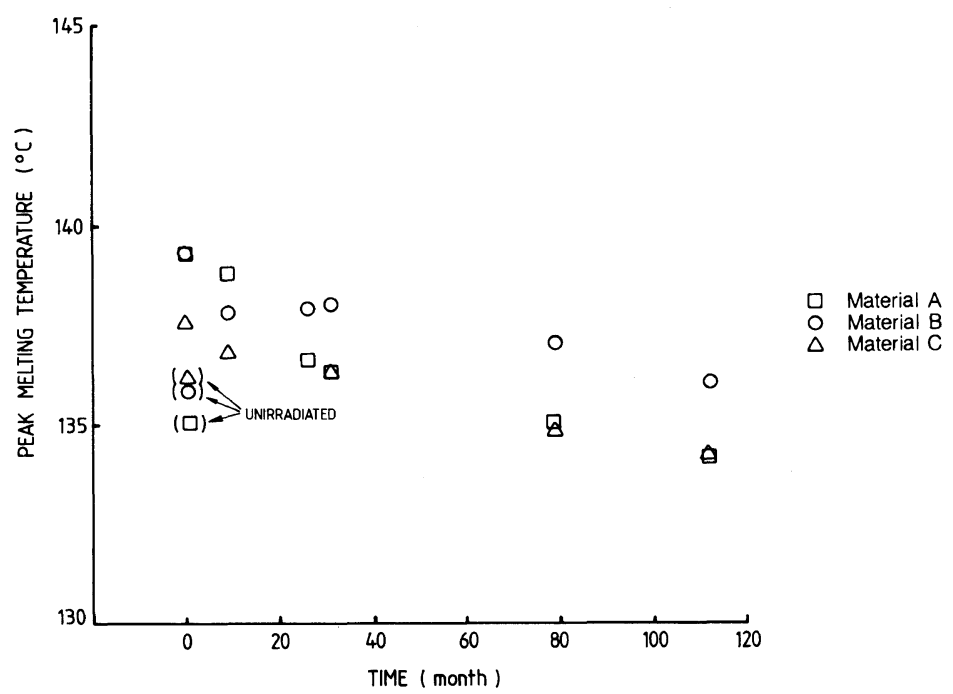

Figure 9. Variation of peak melting temperature with aging time for all three irradiated polyethylenes (exposed to a radiation dose of $16 \mathrm{Mrad}$ ). 


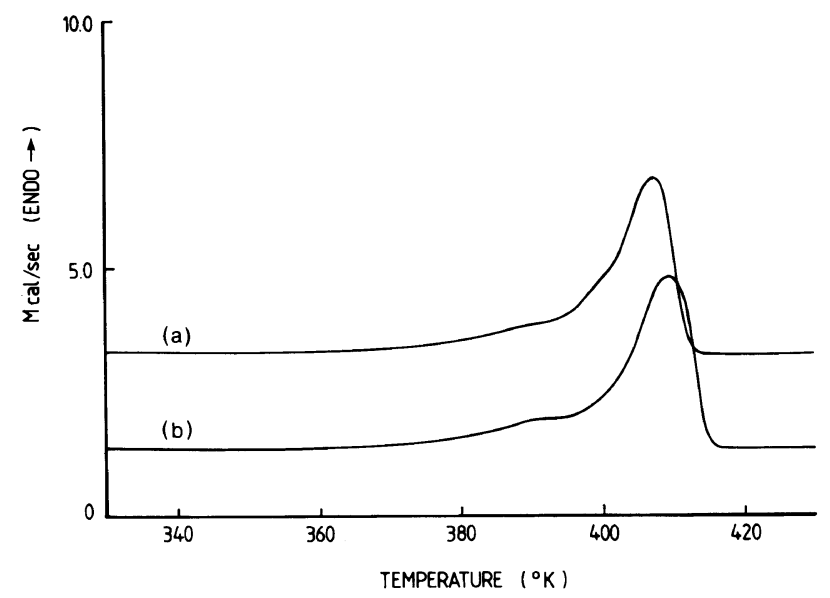

Figure 10. The DSC traces for irradiated material B (64 Mrad), aged for (a) 79 months, and (b) 112 months.

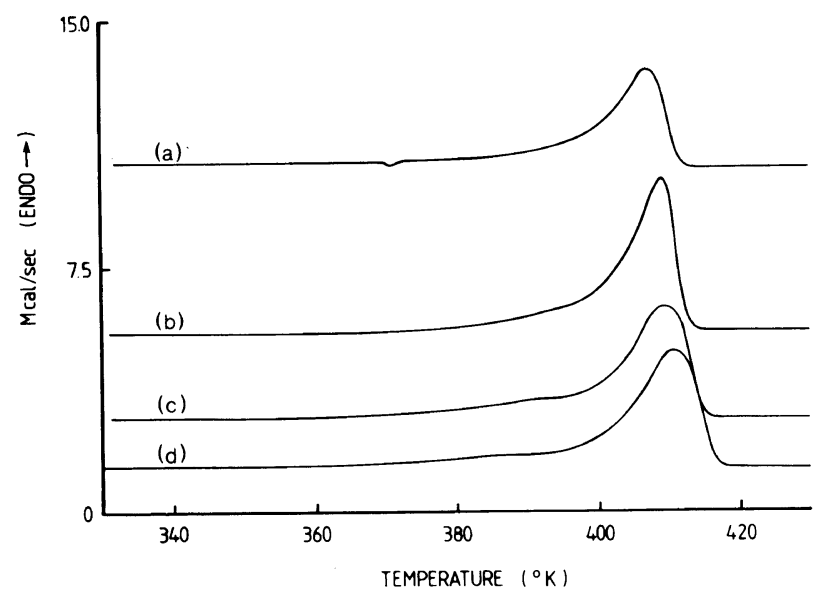

Figure 11. The DSC traces for irradiated material B, aged for 112 months, the radiation dose being: (a) $0 \mathrm{Mrad}$, (b) $16 \mathrm{Mrad}$, (c) $64 \mathrm{Mrad}$, and (d) $128 \mathrm{Mrad}$.

growth of low-melting point crystals. It is interesting to compare these observations with Figure 4, when it is immediately clear that the low-temperature process only emerges in the thermograms after the major rise in $h_{\mathrm{f}}$ is complete, that is, after 31 months. We suggest that in the period 31 months onward so little amophous material remains available for crystallization (effectively none in HDPE) that only very thin lamellae can grow, and it is these thin crystals that cause the lowtemperature shoulder or peak. At higher doses there is more cross-linking which further restricts the growth of crystals and so the lamellae are even thinner at high doses. Hence the low-temperature shoulder/peak moves to lower temperatures at higher doses.

\section{DISCUSSION}

It will be convenient to divide this discussion into several sections each dealing with a different time-period. Thus we shall consider first the events occurring during the first day, then 
with the period from one day to 31 months and finally with the period between 31 and 112 months.

\section{Aging Processes during the First Day}

At some time during the first day following irradiation, the heat of fusion rises significantly for UHMWPE but only marginally, if at all, for HDPE. This rise is virtually independent of irradiation dose. At the same time, the peak melting temperature for all the polymers studied increases significantly. We do not know whether these effects occur immediately upon irradiation or whether they develop over $24 \mathrm{~h}$.

There are several possible mechanisms for these initial aging effects, and these are as follows:

1) Severance of tie molecules by irradiation followed by rapid consequent readjustment of structure without crystal growth.

2) As (1) but with crystal lamellar thickening or new lamellar growth.

3) Radiation cross-linking in the amorphous phase or lamellar surfaces.

Considering these in reverse order, crosslinking might increase $T_{\mathrm{m}}$ by reducing the entropy of fusion (the melt is more constrained than in the absence of cross-links), but could hardly result in an increased $h_{\mathrm{f}}$. Any intracrystalline cross-links would reduce $h_{\mathrm{f}}$. Even an increase in $T_{\mathrm{m}}$ is doubtful since lamellae would be less able to anneal during the DSC run to optimize $T_{\mathrm{m}}$ as commonly occurs with uncross-linked polyethylene (sometimes producing spurious double melting peaks).

Moving on to option (2), we have produced considerable evidence in previous publications for the idea that tie molecules are being severed during irradiation. ${ }^{5.9}$ Since these molecules are likely to be under strain due to incorporation in more than one lamella, they would be naturally susceptible to easy fracture since the backbone bonds are already partly energized. Once they break, the lamellae may be free to undergo lamellar thickening, raising both $T_{\mathrm{m}}$ and $h_{\mathrm{f}}$. This is unlikely however, since the specimens are at ambient temperature and no significant annealing effects are normally found in polyethylene at such temperatures. Furthermore, it was found in ref 5 that low angle X-ray studies revealed no change in lamellar thickness.

This leaves option (1), which we favor. The idea here is that severance of the tie molecules relieves strain on the crystal lamellae (the tie molecules could be likened to the guy ropes on a tent). The strain energy built in to the structure by intact tie molecules must reduce the heat of fusion and the melting temperature (this strain energy can be pictured as making a positive contribution to the surface energy). Severance, therefore, would give rise to a spontaneous increase in $h_{\mathrm{f}}$ and $T_{\mathrm{m}}$ as observed, without lamellae thickening or crystal growth. The effects would be smaller in HDPE as is observed, because there would be more tiemolecules in the UHMWPE on account of its longer molecules.

\section{Aging Processes from One Day to 31 Months}

During this period the heat of fusion increases at a slow constant rate which is very much slower than the jump in $h_{\mathrm{f}}$ occurring during the first day and discussed above. The rate of rise of $h_{\mathrm{f}}$ is similar in all three polymers and is not related to the existing degree of crystallinity. Furthermore, in ref 5 we showed that a density increase is recorded during this period without an increase in average lamellar thickness.

This evidence indicates that new lamellar crystals are growing in the amorphous regions, presumably as a result of the severance of tie molecules. The new lamellae must be of similar thickness to those existing before irradiation, since no increase in lamellar thickness is recorded and no low-melting point material appears in the thermograms during this period. We cannot at this time say whether the rate of crystal growth is controlled simply 
by the temperature or also by an ongoing process of tie molecule severance fueled by the decay of free radicals trapped in the immobile crystalline phase. We favor the simpler explanation of a temperature controlled growth rate because there is no effect of existing crystalline/amorphous ratio on the rate (see Figure 4). Oxidation might also contribute.

The effect of dose on the amount of crystal growth that can occur will be determined by the balance between severance of tie molecules and radiation cross-linking of the amorphous phase. At the higher doses the rise in $h_{\mathrm{f}}$ is smaller and the rate of growth slower. This is consistent with the higher effective viscosity of the amorphous phase as cross-linking increases and, of course, the exclusion of crosslinks from the crystal structure. In HDPE these effects are such as to eliminate all increase in $h_{\mathrm{f}}$ at $128 \mathrm{Mrad}$.

During this period also there is a decline in the peak $T_{\mathrm{m}}$ value from that reached after one day. Thus in contrast to the situation during the first day, we have a situation where $T_{\mathrm{m}}$ is falling as $h_{\mathrm{f}}$ (and crystallinity) is rising. If the new lamellae were thin, the effect might be to depress the net $T_{\mathrm{m}}$ and so lower the peak temperature. But there is no evidence that thin lamellae are produced during this period.

The alternative explanation of the decline in $T_{\mathrm{m}}$ is that the growth of new lamellae reestablishes the population of tie molecules destroyed by irradiation and thus the resulting strain energy. This in turn reduces $T_{\mathrm{m}}$. It will also reduce $h_{\mathrm{f}}$ if our previous reasoning is correct, but the growth of new crystals more than compensates for this, giving a net increase in $h_{\mathrm{f}}$. This is the explanation we favor.

\section{Aging Processses from 31 to 112 Months}

During this final period $h_{\mathrm{f}}$ continues to rise in UHMWPE but at a much slower rate than during the first 31 months. In HDPE no further rise occurs in $h_{\mathrm{f}}$. The peak $T_{\mathrm{m}}$ continues to fall in all cases, however, and a shoulder or low-melting peak appears in the
UHMWPE thermograms.

These observations point to a secondary crystallization process involving the development of thin lamellae in the remaining amorphous interstices between the primary lamellae. The growth of these crystals involves unfavorable kinetics and the rate is slow. The amount of this secondary growth is almost negligible in HDPE due to its already high level of crystallinity after-post irradiation growth.

\section{CONCLUSION}

While we do not wish to be dogmatic about the proposed mechanisms, the scenario outlined above seems to provide a satisfactory and consistent explanation of the observed phenomena and one which introduces at least one novel concept. This is the depression of $T_{\mathrm{m}}$ and heat of fusion by the strain energy stored in tie molecules stretched between crystal lamellae. By severing these tie molecules, irradiation facilitates a number of further crystallization processes which lead, importantly, to a considerable enhancement of total crystallinity.

Acknowledgements. The authors would like to thank the Dow Chemical Company for their kind gift to S. K. B of the irradiated and partially aged polyethylene samples, allowing him to continue these studies in the interests of the advancement of science. The authors are also grateful to Messrs. Leigh Nelson and Randall Adam of 3M for their constant support and interest the present work.

\section{REFERENCES}

1. D. R. Gee and T. P. Melia, Polymer, 11, 178 (1970).

2. C. T. Lue, E. J. Ellis, and A. Crugnola, SPE 39th Annual Tech. Conf., Boston, Tech. Papers, 27, 246 (1981).

3. R. J. Roe, E. S. Grood, R. Shastri, C. A. Gosselin, and F. R. Noyes, J. Biomed. Mater. Res., 15, 209 (1981). 
4. S. K. Bhateja, Polymer, 23, 654 (1982).

5. S. K. Bhateja, E. H. Andrews, and R. J. Young, $J$. Polym. Sci., Polym. Phys., 21, 523 (1983).

6. S. K. Bhateja, J. Appl. Polym. Sci., 28, 861 (1983).

7. I. Kamel and L. Finegold, J. Polym. Sci., Polym. Phys., 23, 2407 (1985).

8. A. Shinde and R. Salovey, J. Polym. Sci., Polym. Phys., 23, 1681 (1985).

9. S. K. Bhateja and E. H. Andrews, J. Mater. Sci., 20, 2839 (1985).

10. M. Kurth, P. Eyerer, and D. Cui, "Effects of Radiation Sterilization on UHMWPE," SPE 45th
Annual Tech. Conf. and Exhibit, Los Angeles, May, 1987, p 1193.

11. S. K. Bhateja, J. Macromol. Sci., Phys., B22, 159 (1983).

12. O. Gal, D. Kostoski, D. Babic, and V. T. Stannett, Radiation Phys. Chem., 28, 259 (1986).

13. V. Aslaian, V. Vardanian, M. Avetesian, S. Felekian, and S. Ayvasian, Polymer, 28, 755 (1987).

14. M. Dole, Polym.-Plast. Technol. Eng., 13, 41 (1979).

15. A. K. Mukherjee, B. D. Gupta, and P. K. Sharma, J. Macromol. Sci., Revs. Mcromol. Chem. Phys., C26, 415 (1986). 